\title{
PENINGKATAN CARA MENGAJAR GURU
}

\section{MELALUI SUPERVISI PENDIDIKAN}

\author{
SARAH BEUTY
}

\author{
Email : $\underline{\text { sarahbeuty47@gmail.com }}$
}

\begin{abstract}
Abstrak
Kualitas dari pembelajaran tergantung pada kualitas kinerja guru. Kinerja guru mempengaruhi prosess belajar memgajar. Dalam prosesnya kepala sekolah dapat melakukan supervisi terhadap guru untuk memabantu guru mengatasi kesulitan yang dihadapinya. Tugas dari seorang supervisor adalah mendorong, membantu, dan memberikan keyakinan kepada guru. Supervisi dilakukan melalui bayak tahap penyelesaian masalah belajar mengajar dan tujuannya adalah supaya dapat meningkatkan proses pembelajaran.
\end{abstract}

Kata kunci : Kepala Sekolah, Supervisi, dan Guru.

\section{Pendahuluan}

Menurut Maralih(Maralih, 2014) dalam jurnalnya yang berjudul Peranan Supervisi Dalam Peningkatan Kualitas Pendidikan Sekolah adalah lembaga pendidikan formal yang terencana dan strategis yang bertujuan untuk mampu meningkatkan kualitas pendidikan. Maka diperlukan peningkatan kualitas SDM di sekolah yaitu supervisor dan pendidik.

Kesuksesan pendidikan di sekolah ditentukan oleh pendidik, karena pendidik adala sebagai fasilitator dan sekaligus sebagai pusat pembelajaran. Kegiatan guru sebagai pendidik menjadi pijakan dalam mencapai tujuan pendidikan dalam sekolah. Apapun yang dilakukan guru dalam proses belajar mengajar, memberikan pengaruh terhadap proses pembelajaran.

Untuk mencapai tujuan pendidikan. Peningkatan kualitas pendidikan perlu ditingkatkan. Dalam melaksanakan tugas, seorang guru memerlukan pembimbing supaya dapat mengembangkan kemampuannya dalam proses pembelajaran. Dalam hal itu guru memerlukan bimbingan dari seorang supervisor. Supervisi merupakan proses yang dirangkai secara khusus guna membantu guru dalam melaksanakan tugas di sekolah agar dapat mengaplikasikan pengeahuan dan keterampilan untuk layanan yang lebih baik pada siswa.

Peningkatan cara mengajar guru melalui supervisi ini bisa dilakukan oleh kepala sekolah. Seorang kepala sekolah memiliki wewenang untuk melakukan pembinaan atau supervisi terhadap guru. Bagi kepala sekolah yang mlakukan pembinaan atau supervisi, akan Nampak perbedaannya jika dibandingkan dengan yang tidak melakukan pembinaan atau supervisi. Karena dengan adanya pembinaan atau supervisi tersebut, Kepala sekolah dapat memantau dan mengkoreksi apa saja yang dilakukan oleh seorang guru ketika melakukan proses belajar mengajar. Dengan manfaat dari pembinaan atau supervisi itulah kekurangan guru dapat segera dihilangkan sehingga pembelajaran dapat berjalan dengan lancer dan cara mengajar guru dapat meningkat kualitasnya.

Adapun rumusan masalah dalam artikel ini adalah bagaimana meningkatkan cara mengajar guru melalui supervisi pendidikan, dan 
Adapun tujuan dari penulisan artikel ini adalah untuk mengetahui hal-hal yang dapat meningkatkan cara mengajar guru melalui supervisi pendidikan.

\section{Pembahasan}

\section{Supervisi}

Menurut Sabandi (Sabandi, 2013) dalam jurnalnya yang berjudul Supervisi Pendidikan Untuk Pengembangan Profesionalitas Guru Berkelanjutan bahwa supervisi pendidikan berkembang seiring berkembangnya zaman. Seperti pengetahuan, teknologi, ekonomi, social dan budaya yang ada di masyarakat.

Supervisi pendidikan yaitu usaha untuk mendorong, mengatur dan membimbing secara berkelanjutan pertumbuhan guru di sekolah agar pendidik paham dan lebih efesien dalam mewujudkan semua fungsi pengajaran dan mereka dapat memantau dan membimbing pertumbuhan peserta didik, sehingga mereka mampu dan lebih kompeten berpartisipasi dalam masyarakat.

Supervisi dapat diartikan sebagai yang dilakukan oleh pengawas dan pimpinan sebagai pejabat yang lebih tinggi dari guru untuk memantau atau mengawasi pekerjaan pendidik (guru). Supervisi jjga dapat diartikan sebagai kegiatan Kepala Sekolah yang dilakukan untuk tujuan perbaikan proses belajar mengajar di sekolah. Terdapat dua tujuan yang harus diwujudkan oleh supervisor, yaitu (1) perbaikan pendidik dan peserta didik (2) meningkatkan mutu pendidikan.

\section{Kegiatan Supervisi}

Tujuan dari kegiatan supervisi yaitu untuk menjaga dan melindungi kualitas pendidik dalam proses belajar mengajar di sekolah. Kegiatan supervisi sangat penting jika ingin kualitas pendidikan yang lebih baik di sekolah, karena supervisi merupakan pertolongan terhadap guru. Tujuan dari supervisi yaitu memberikan pelayanan untuk memperbaiki kualitas mengajar pendidik di kelas. Tujuan pendidikan bagi supervisor adalah untuk membantu pendidik di sekolah supaya mampu menjalankan tugas sebagai tenaga pendidik secara menyeluruh untuk menghasilkan situasi pembelajaran yang lebih efektif dan efesien.

Fungsi suprvisi pendidikan meliputi empat fungsi utama, yaitu (1) penelitian (2) penilaian (3) perbaikan, dan (4) peningkatan. Supervisi yang dijlankan berkaitan dengan tugas pndidik, yaitu (1) keahlian dalam merencanakan pengajaran (2) keahlian dalam mengimplementasikan pengajaran, dan (3) kahlian dalam menilai pembelajaran.

Ada beberapa prinsip yang perlu diperhatikan dalam melakukan supervise pendidikan yaitu (1) ilmiah (2) demokrasi (3) kooperatif (4) kreatif.

\section{Pelaksanaan supervisi}

Supervisi dapat dilakukan oleh pengawas, kepala sekolah, wakil kepala sekolah, bidang kurikulum atau akademik, wali kelas, petugas nk, dan petugas perpustakaan, dan inti supervisi adalah guru dan pegawai.

Yang menjadi tujuan utama dari supervisi pendidikan adalahg guna melakukan bimbingan terhadap pendidik agar bisa melakukan tugas dengan baik. Supervisor harus bisa mengendalikan 
dan mensupervisi terhadap tenaga kependidikan dengan tujuan meningkatkan profesional guru dan kualitas pengajaran.

Ada beberapa teknik supervisi yang dapat digunakan supervisor yaitu (1) teknik kunjungan kelas (2) teknik kunjungan sekolah (3) teknik kuis dadakan (4) teknik angket (5) teknik observasi dokumen (6) teknik wawancara (7) teknik angket (8) teknik laporan. Kepala sekolah melakukan supervisi terhadap guru meliputi (1) masalah profesional guru (2) masalah kehadiran (3) masalah kematangan mengajar guru (4) masalah pencapaian tujuan dari pelaksanaan ekstrakulikuler (5) penguasaan bahan ajar. Kegiatan supervisi yang dilakukan oleh seorang supervisor adalah merencanakan pprogram, melaksanakan supervisi dan menindaklanjuti supervisi.

\section{Upaya meningkatkan cara mengajar guru melalui supervisi}

Untuk dapat melakukan pembelajaran yang berkualitas dan kinerja yang baik, maka guru harus memiliki kompetensi. Seperti yang sudah diatur dalam Undang-Undang No. 14 Tahun 2005 pasal 10 ayat 1 tentang guru dan dosen bahwa kompetensi yang harus dimiliki oleh guru adalah kompetensi pedagogik, kompetensi kepribadian, kompetensi kepribadian, kompetensi sosial, dan kompetenso profesional yang diperoleh melalui profesi. Mutu pendidikan tergantung pada prestasi guru yang profesional. Mampu dalam pengelolaan kelas dan melengkapi administrasi yang mendukung prestasi siswa, mampu merumuskan kompetensi siswa dalam bidang pelajaran yang dikelola guru, merencanakan dan melaksanakan pembelajaran serta mengevaluasi hasil belajar peserta didik dapat menggunakan teknik dan metode yang telah dikuasai guru. Guru juga harus mampu menyusun mata pelajaran dengan mendesain karakteristik dan standar program. Selain itu guru juga harus memahami dan melaksanakan kode etik (Sallis, 2012:109-110, Santori,2008:6.1, Umaedi,2009:6.19, Wahyudin,2007:9.33)

Kepala sekolah sebagai pemimpin diharapkan melakukan moitoring dan bimbingan secara menyeluruh terhadap proses belajar mengajar, sehingga apabila terjadi permasalahan dan kesulitan dialami oleh guru maupun siswa sendiri. Melalui sistem monitoring ini, kepala sekolah lebih mudah memantau sehingga akan lebih mudah mengetahui mana guru yang efektif dan profesional dan mana yang tidak.

Kesimpulan

Sekolah adalah lembaga pendidikan formal yang terencana da strategis yang bertujuan untuk mampu dalam meningkatkan kualitas pendidikan. Kesuksesan pendidikan di sekolah ditetapkan oleh pendidik, karena pendidik adalah sebagai fasilitator dan sekaligus sebagai pusat pembelajaran. Kegiatan guru sebagai pendidik menjadi pijakan dalam mencapai tujuan pendidikan dalam sekolah. Apapun yang dilakukan guru dalam proses belajar mengajar, memberikan pengaruh terhadap proses belajar.

Untuk meningkatkan kinerja guru dalam proses pembelajaran ada hal yang dapat dilakukan oleh supervisor. Kepala sekolah sebagai supervisor dapat melakukan supervisi terhadap guru untuk meningkatkan cara mengajar guru di dalam kelas, dimana hasil supervisi dapat dijadikan evaluasi proses belajar mengajar guru.

\section{Saran}


Supervisi harus dilakukan dalam jangka waktu yang berkala oleh kepala sekolah. Kepala sekolah harus melakukan supervisi terhadap guru untuk membimbing dan membantu guru dalam menghadapi kesulitan yang dihadapi oleh guru.

\section{References}

Maralih. (2014). PERANAN SUPERVISI DALAM PENINGKATAN KUALITAS

PENDIDIKAN. Qathruna, 1(1), 1-14. Retrieved from

http://jurnal.uinbanten.ac.id/index.php/qathruna/article/download/251/250/

Sabandi, A. (2013). SUPERVISI PENDIDIKAN UNTUK PENGEMBANGAN PROFESIONALITAS GURU BERKELANJUTAN. Pedaogi, Jurnal Ilmiah Ilmu Pendidikan, XIII(2), 1-9. Retrieved from

http://ejournal.unp.ac.id/index.php/pedagogi/article/viewFile/4275/3345 